\title{
ADNEXAL TORSION - MANAGEMENT AND REVIEW OF LITERATURE
}

\author{
Maneesha Shrivastava ${ }^{1}$, Ashwin Apte ${ }^{2}$, Roshan Chanchlani ${ }^{3}$
}

\section{HOW TO CITE THIS ARTICLE:}

Maneesha Shrivastava, Ashwin Apte, Roshan Chanchlani. "Adnexal Torsion- Management and Review of Literature". Journal of Evolution of Medical and Dental Sciences 2014; Vol. 3, Issue 10, March 10; Page: 26322638, DOI: $10.14260 /$ jemds/2014/2185

ABSTRACT: BACKGROUND: Ovarian torsion presents as acute abdominal pain and early surgical management is required to prevent further adnexal damage. It accounts for $3 \%$ of all cases of acute abdominal pain in adult women. As signs and symptoms can mimic other acute abdominal conditions, the preoperative diagnosis often remains a challenge for primary care physicians. AIMS AND OBJECTIVES: To study the characteristics of adnexal torsion and factors influencing adnexal preservation. MATERIAL AND METHODS: All 14 patients were admitted in a tertiary endoscopic surgical unit with the complaints of pain in abdomen, nausea and vomiting of varying duration. The minimum duration of symptoms was 3 days and a maximum of 1 year. All patients were evaluated by ultrasound examination preoperatively. The time interval between the onset of symptoms and definitive surgery varied from 3 days to one year. Laparoscopic approach was offered to all patients except one where the patient was antenatal at 10 weeks of gestation. RESULTS: Out of 14 patients the youngest patient was a neonate 28 days old and oldest was 68 years of age. Most patients $(n=9)$ were between 10 to 30 years of age. Intra operatively complete torsion (torsion of both ovary and fallopian tube) was found in 9 cases, 3 were torsion of hydrosalpinx and one case was torsion of a paraovarian cyst. One case was torsion of the adnexa in antenatal period. Adnexal congestion and edema was the most common finding $(n=6)$ simulating hemorrhagic cyst. One patient the oldest in series age 68 years had torsion of an ovarian mass which was histologically confirmed as mucinous cystadenoma. Two patients had ovarian dermoid where ovary was salvaged in one by doing cystectomy and in the other a salpingoophorectomy was performed. In one patient it was torsion of parovarian cyst where cyst wall excision was performed. In antenatal at 11 weeks gestation a mini laparotomy was performed under epidural analgesia and detorsion was performed. In all 4 patients who had hydrosalpinx $(n=3)$ and parovarian cyst $(n=1)$, a salpingectomy and cyst excision was performed respectively. In rest with complete torsion ( $n=9$, excluding fetal adnexal torsion) ovarian preservation was possible in 4 patients (44.45\%) and 5 patients (55.55\%) required oophorectomy. CONCLUSION: Adnexal torsion affects all ages of women and ovarian preservation is possible, if detorsion is possible. Delay in diagnosis prevents ovarian preservation. Though limited by small sample size it indicated that ovarian debulking may not be needed and detorsion relieves the venous congestion and edema. Laparoscopic approach remains the gold standard for the management of adnexal torsion and enables quick recovery.

INTRODUCTION: The annual prevalence of ovarian torsion is estimated to be 4.9 per 100000 females aged 1 to 20 years. Adnexal torsion is the fifth most common surgical emergency in gynecology and mostly affects the younger age group. ${ }^{1}$ Of all cases of ovarian torsion that occur, nearly three-fourths present during the reproductive years from 20 to 40 years of age, and few occur in postmenopausal women. Overall, about $15 \%$ of cases occur during infancy and childhood ${ }^{2}$. It is diagnosis that must be considered in all girls and young women presenting with abdominopelvic pain 
and mass. Adnexal torsion is primarily a clinical diagnosis based on a thorough history and meticulous examination. The typical clinical history in ovarian torsion is of sudden onset of severe unilateral, lower abdominal pain of intermittent nature. Nausea and vomiting is present in $70 \%$ of cases. The clinical presentation is often nonspecific with few distinctive physical findings commonly resulting in delay of diagnosis and appropriate surgical management. ${ }^{3}$ The condition is associated with reduced venous return from the ovary resulting in stromal edema congestion and internal hemorrhage. Further delay causes necrotic changes leading to peritoneal signs and symptoms. A prompt diagnosis and intervention is required to save adnexal structures from infarction enabling adnexal preservation 4

\section{MATERIAL AND METHODS:}

Study design: A retrospective observational study of patients presenting with adnexal torsion in all age groups in a single center in one year (Jan 2013 to Dec 2013).

Setting: A tertiary Endoscopic surgical unit.

Sample: Females presenting with pelvic pain and adnexal lesion.

The institutional ethical committee approval was taken.

MATERIALS AND METHODS: All patients were admitted in a tertiary endoscopic surgical unit with the complaints of pain in abdomen, nausea and vomiting of varying duration. The minimum duration of symptoms was 3 days and maximum of 1 year. One case was a neonate wherein the cyst was diagnosed in abdominopelvic region on antenatal ultrasound. Data on the type of surgical approach used to visualize the ovary, surgical findings, surgical procedure for treatment of the ovarian torsion, pathological results were analyzed. Laparoscopic approach was offered to all patients except one where the patient was antenatal at 10 weeks of gestation.

RESULTS: The age of patients at presentation was as in (table 1). The youngest patient was a neonate of 28 days and oldest was 68 years of age. Most patients $(n=9)$ were between 10 to 30 years of age.

\begin{tabular}{|c|c|c|}
\hline Age in years & No of cases $\mathbf{n = 1 4}$ & $\%$ \\
\hline $0-10$ & 2 & 14.28 \\
\hline $11-20$ & 4 & 28.57 \\
\hline $21-30$ & 5 & 35.71 \\
\hline $31-40$ & 2 & 14.28 \\
\hline$>40$ & 1 & 7.14 \\
\hline
\end{tabular}

Table 1: Age of patients admitted with suspected torsion

All patients were evaluated by ultrasound examination preoperatively and the findings are summarized in (table 2). The Doppler findings were normal in patients with hemorrhagic cyst however; Doppler examination was not done in patients with complex adnexal mass and dermoid cyst. 


\begin{tabular}{|l|c|}
\hline Ultrasonography imaging findings & n=14 \\
\hline Hemorrhagic cyst & 8 \\
\hline Complex adnexal mass & 4 \\
\hline Dermoid cyst & 2 \\
\hline $\begin{array}{l}\text { Table 2: Findings in preoperative ultrasound } \\
\text { done in patients of suspected adnexal torsion }\end{array}$
\end{tabular}

The time interval between the onset of symptoms and definitive surgery varied from 3 days to one year.

\begin{tabular}{|l|c|}
\hline Time interval (days) & $\mathbf{n = 1 3}$ (fetal adnexal torsion excluded) \\
\hline $0-7$ & 2 \\
\hline $8-15$ & 5 \\
\hline $16-30$ & 2 \\
\hline$>30$ days & 4 \\
\hline \multicolumn{2}{|r|}{$\begin{array}{r}\text { Table 3: Time interval between onset of } \\
\text { symptoms and definitive surgery }\end{array}$} \\
\hline
\end{tabular}

Intra operatively complete torsion (torsion of both ovary and fallopian tube) was found in 9 cases, 3 were torsion of hydrosalpinx and one case was torsion of a parovarian cyst. One case was torsion of the adnexa in antenatal period. Laparoscopy was done on 28 $8^{\text {th }}$ day of life when a congested and necrotic cyst of $5 \mathrm{~cm}$ with torsion of the pedicle was found at a higher level than the normal ovarian fossa with the ovarian fossa being empty. (Fig 1, 2) Fetal ovarian torsion led to complete non development of right adnexa due to ischemia ${ }^{5}$. Adnexal congestion and edema was the most common finding $(n=6)$ simulating hemorrhagic cyst. In patients with chronic torsion, who were receiving symptomatic treatment for over a month dense omental adhesions along with bowel loops and encysted loculated collection was present on laparoscopy.

These were reported as complex adnexal mass on imaging. One patient the oldest in series age 68 years had torsion of an ovarian mass which was histologically confirmed as mucinous cystadenoma. A unilateral salpingoophorectomy was performed laparoscopically. Two patients had ovarian dermoid where ovary was salvaged in one by doing cystectomy and in the other a salpingoophorectomy was performed. In one patient it was torsion of parovarian cyst where cyst wall excision was performed. In antenatal at 11 weeks gestation a mini laparotomy was performed under epidural analgesia and detorsion was performed.

\begin{tabular}{|l|c|}
\hline \multicolumn{1}{|c|}{ Intraoperative finding } & $\mathbf{n = 1 4}$ \\
\hline Adnexal congestion and edema & 6 \\
\hline Complex ovarian tumor & 1 \\
\hline Dermoid & 2 \\
\hline Omental adhesions and tuboovarian mass & 4 \\
\hline Parovarian cyst & 1 \\
\hline
\end{tabular}

Table 4: Intraoperative findings 
In all 4 patients who had hydrosalpinx $(n=3)$ and parovarian cyst $(n=1)$, a salpingectomy and cyst excision was performed respectively. In rest with complete torsion ( $\mathrm{n}=9$, excluding fetal adnexal torsion) ovarian preservation was possible in 4 patients $(44.45 \%)$ and 5 patients $(55.55 \%)$ required oophorectomy.

All patients who underwent the procedure by laparoscopic approach were discharges in 24 hours; however antenatal patient who underwent mini laparotomy was kept under observation for 48 hours.

All patients in whom ovarian preservation was done were followed up at 7 days and at 45 days post operatively with ultrasound and Doppler examination to reveal normal findings. There was one readmission at second post -operative day with pain in pelvic region which responded to antiinflammatory agents. In this patient ultrasound examination was performed early which revealed normal ovarian morphology and Doppler study.

DISCUSSION: Adnexal torsion is a gynecological emergency that affects all ages and even fetal period. ${ }^{6}$ Several studies have been conducted on heterogeneous population of neonates, premenarchal girls, adolescents, and others having adnexal masses and incidence was maximum between 10-30 years of age, this was also seen in our study.7-9 The factor influencing ovarian preservation is high index of suspicion and intervention at the earliest enabling detorsion. The use of Ultrasonography in the diagnosis of ovarian torsion was demonstrated to have low specificity. ${ }^{10}$ The search for a better modality of imaging in the diagnosis of Ovarian Torsion led to the suggestion of Doppler flow studies used to evaluate compromise in arterial or venous blood flow to the affected ovary. Its role as a predictor of torsion, however has elicited similar controversy. ${ }^{6-13}$

In our study The Doppler findings were normal in patients with hemorrhagic cyst however Doppler examination was not done in patients with complex adnexal mass and Dermoid cyst. Laparoscopic approach was offered to all patients in our study except one where the patient was antenatal at 10 weeks of gestation. The advantages of laparoscopy in the diagnosis and treatment of pelvic masses in gynecology are well established.5,14-16

It was the preferred surgical approach in our series as well. Time plays an important role in the effort to conserve involved adnexa. Rousseau et al $^{17}$ reported an inverse relationship between the time interval from admission to diagnosis and to performing conservative surgery. In our series cyst excision was performed only in case of Dermoid and in the rest no attempt to debulk the ovary or drain the cyst was done. It was evident that (Fig 3) the appearance of hemorrhagic cyst is due to ovarian congestion and reduced venous return leading to ovarian edema. As mentioned earlier, cystectomy was performed only in the presence of pathological cyst (Dermoid).

In all patients who presented within one week and had complete torsion ovarian preservation was possible with detorsion only (Fig. 4). Though detorsion was possible in fallopian tube torsions also, a salpingectomy was performed due to presence of large hydrosaplinx. (Fig. 6) It was observed that patients who presented late (Fig. 5) had adhesions and fibrosis at the adhesion site and could not be detorted as during the attempt to do so it was noted that there was no vascularity in the pedicle. It was evident as there was no bleeding even while transecting the pedicle without ant use of diathermy.

In our series we did not notice any recurrence even though ovariopexy was not done. There has been the growing trend towards a more conservative approach in the treatment of Ovarian 
Torsion and previous studies of successful conservative laparoscopic approach for such cases and negligible cases of cancer detected in various series favor the conservative approach which corroborate in our study as well. ${ }^{18}$

CONCLUSION: Adnexal torsion affects all ages of women and ovarian preservation is possible if detorsion is possible. Delay in diagnosis prevents ovarian preservation. It was also noted that Doppler examination is not a very reliable tool in the diagnosis of adnexal torsion. Though limited by small sample size it indicated that ovarian debulking may not be needed and detorsion relieves the venous congestion and edema. Timely Laparoscopic approach remains the gold standard for the management of adnexal torsion and enables quick recovery.

\section{REFERENCES:}

1. Growdon W B, Laufer M R. Ovarian and Fallopian Tube Torsion. Available from: http://www.uptodate.com/contents/ovarian-and fallopian-tube-torsion.

2. Darrell L. Cass, MD. Ovarian torsion, Seminars in Pediatric Surgery (2005) 14, 86-92.

3. Emonts M, Doornewaard H, Admiraal JC. Adnexal torsion in very young girls: diagnostic pitfalls. Eur J Obstet Gynecol Reprod Biol 2004; 116:207-10.

4. Balci O, Icen MS, Mahmoud AS, Capar M, Colakoglu MC. Management and outcomes of adnexal torsion: a 5-year experience. Arch Gynecol Obstet. 2011 Sep; 284(3):643-6.

5. Focseneanu MA, Omurtag K, Ratts VS, Merritt DF. The auto-amputated adnexa: a review of findings in a Pediatric Population. J Pediatr Adolesc Gynecol. 2013 Dec; 26(6):305-13.

6. Dimitraki M, Koutlaki N, Nikas I, Mandratzi T, Gourovanidis V, Kontomanolis E, Zervoudis S, Galazios G, Liberis V. Fetal ovarian cysts. Our clinical experience over 16 cases and review of the literature. J Matern Fetal Neonatal Med. 2012 Mar; 25(3):222-5.

7. Oltmann SC, Fischer A, Barber R, Huang B, Garcia N. Cannot exclude torsion-a 15 year review. J. Paediatr Surg 2009; 44:1212-1216.

8. Servaes S, Zurakowski D, Laufer MR, Feins N, Chow J S. Sonographic findings of ovarian torsion in children. Paediatr Radiol.2007; 37:446-451.

9. Galinier P, Carfagna L, Delsol M, et al Ovarian torsion. Management and ovarian prognosis: a report of 45 cases. J Paediatr Surgery.2009; 44:1759-1765.

10. Chang YJ, Yan DC, Kong MS, et al. Adenexal torsion in children. Pediatr Emerg Care 2008; 24:534-537.

11. Darrell L. Ovarian torsion Semin Pediatr Surg.2005; 14:86-92.

12. Celik A, Ergun O, Aldemir $\mathrm{H}$ et al. Long term results of conservative management of adnexal torsion in children J Paediatr Surg 2005;40:704-708.

13. Stark JE, Siegel MJ. Ovarian torsion in prepubertal and pubertal girls: sonographic findings. AJR Am J Roentgeol. 1994; 163:1479-1482.

14. Mayer JP, Bettolli M, Kolberg-Schwerdt A, et al. Laparoscopic approach to ovarian mass in children and adolescents: already a standard in therapy. J Laparoendosc Adv Surg Tech A. 2009;19 (suppl 1):S111-S115.

15. Mais V, Ajossa S, Piras B. Treatment of nonendometric benign adnexal cysts: a randomized comparison of laparoscopy and laparotomy. Obstret Gynecol. 1995; 86: 770-774. 


\section{ORIGINAL ARTICLE}

16. Yuen PM, Yu KM, Yip SK. A randomised, prospective study of laparoscopy and laparotomy. Obstet Gynecol. 1977; 177: 109-114.

17. Rousseau V, Massicot R, Dwarish AA et al .Emergency management and conservative surgery of ovarian torsion in children; a report of 40 cases. J Pediatr Adolesc Gynaecol 2008; 21: 201-206.

18. Pansky M, Abargil A, Dreazaen E, Golan A, Bukovsky I, Herman A. Conservative management of adnexal torsion in premenarchal girls. J Am Assoc Gynaecol Lapar. 2000; 7: 121-124.

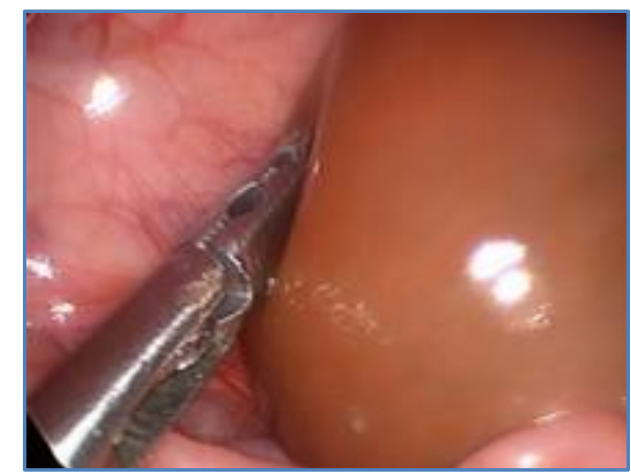

Fig. 1: Right Adnexal torsion in fetal period Laparoscopic view at day 28 of life

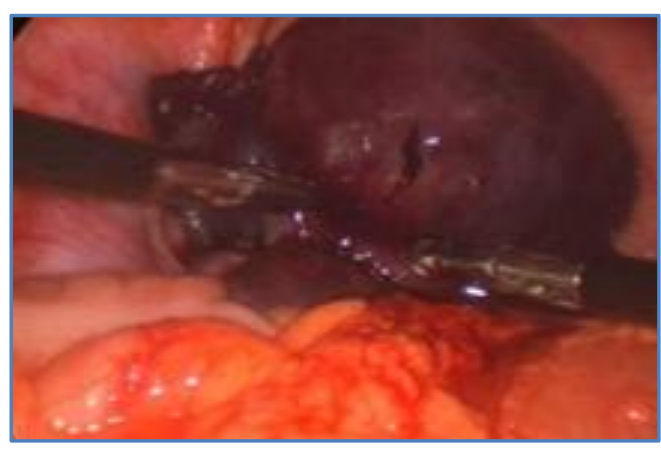

Fig. 3: Adnexal congestion with complete torsion

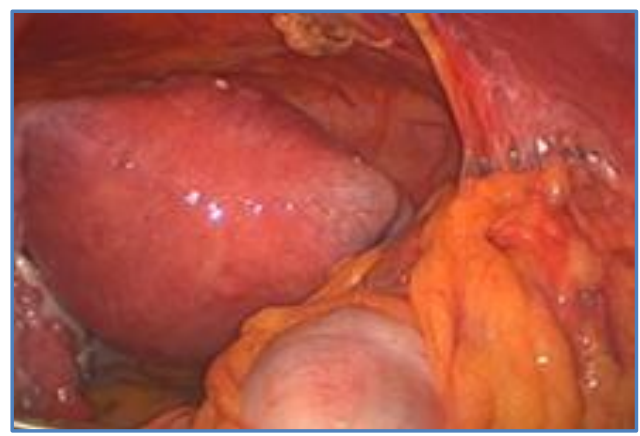

Fig. 5: Chronic adnexal torsion with adhesions

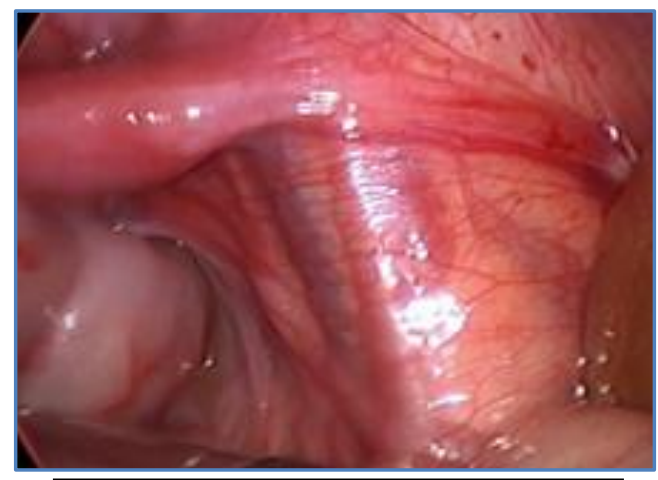

Fig. 2: Empty right ovarian fossa

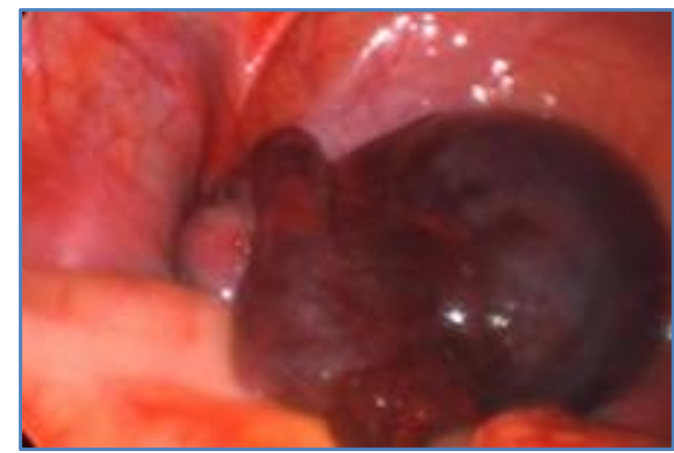

Fig. 4: Adnexa detorted and reduction in congestion noted

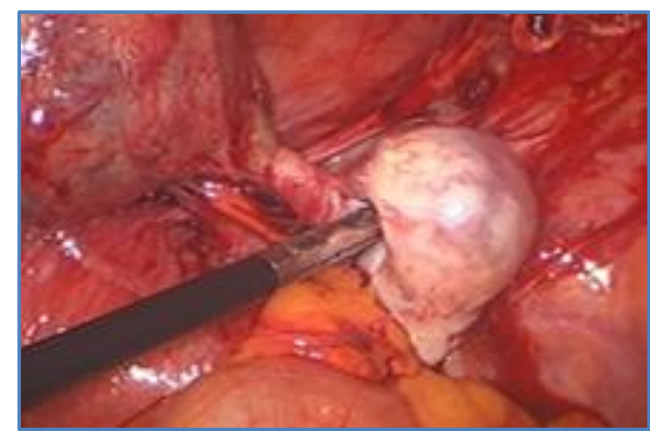

Fig. 6: Chronic torsion of hydrosalpinx 


\section{ORIGINAL ARTICLE}

\section{AUTHORS:}

1. Maneesha Shrivastava

2. Ashwin Apte

3. Roshan Chanchlani

\section{PARTICULARS OF CONTRIBUTORS:}

1. Assistant Professor, Department of Obstetrics and Gynaecology, Chirayu Medical College and Hospital, Bhopal.

2. Associate Professor, Department of Surgery, Chirayu Medical College and Hospital, Bhopal.

3. Associate Professor, Department of Surgery, Chirayu Medical College and Hospital, Bhopal.

\section{NAME ADDRESS EMAIL ID OF THE} CORRESPONDING AUTHOR:

Dr. Roshan Chanchlani, 1/6 - Idgah Kothi, Doctors Enclave, Near Filter Plant, Idgah Hills, Bhopal - 462001, M. P. E-mail: roshanchanchlani@gmail.com

Date of Submission: 13/02/2014. Date of Peer Review: 14/02/2014. Date of Acceptance: 18/02/2014. Date of Publishing: 07/03/2014. 